Supplement of Mech. Sci., 12, 1061-1071, 2021

https://doi.org/10.5194/ms-12-1061-2021-supplement

(c) Author(s) 2021. CC BY 4.0 License.

(c) (i)

Supplement of

\title{
Structural synthesis of plane kinematic chain inversions without detecting isomorphism
}

\section{Jinxi Chen et al.}

Correspondence to: Rongjiang Cui (cuirongjiang2009@163.com)

The copyright of individual parts of the supplement might differ from the article licence. 
The computer programme code for synthesizing kinematic chain inversions is provided as follows.

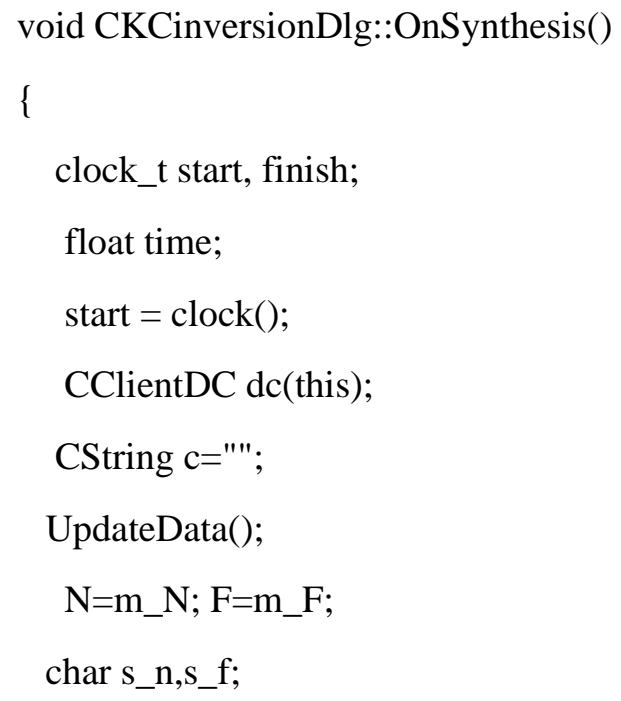

CStdioFile fileinversion;

fileinversion.Open("inversion.txt",CFile::modeReadWrite);

fileinversion.SeekToBegin();

CString str2="';

bool sign=false;

while(fileinversion.ReadString(str2))

\{

if(str2==str1) $\{$ sign=true; break; $\}$

\}

if(sign==true) MessageBox("The inversions have been synthesized!");

else

\{

fileinversion.SeekToEnd();

fileinversion.WriteString(str1);

fileinversion.WriteString("ไn");

CStdioFile fileKC;

fileKC.Open("KCmatrix.txt",CFile::modeRead); 


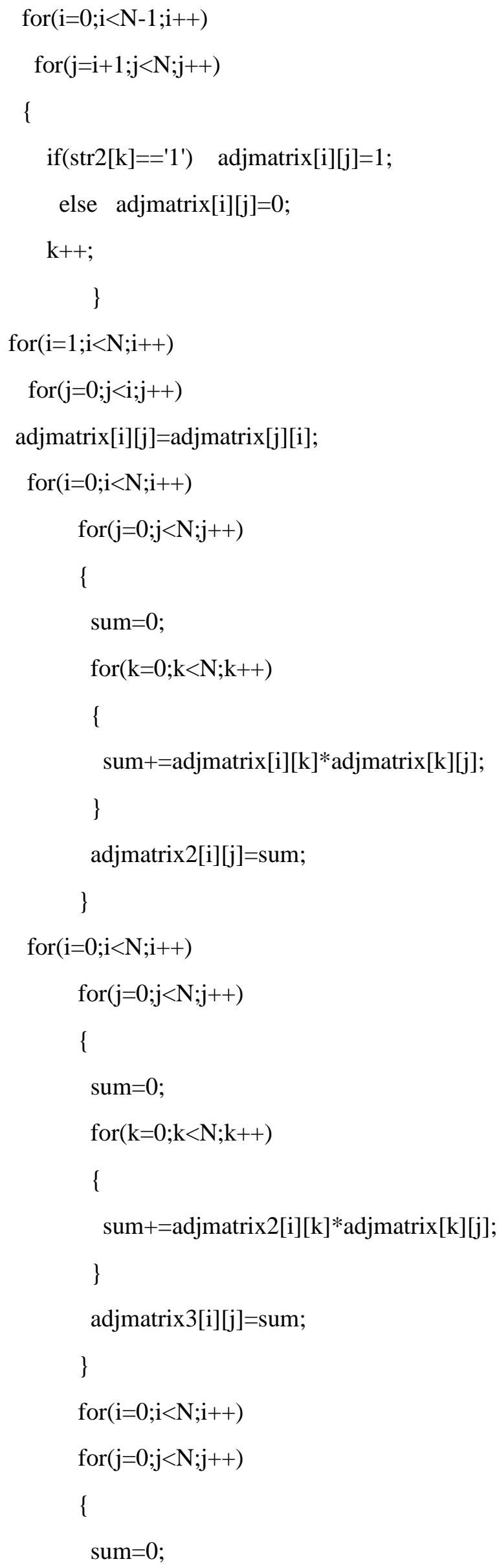




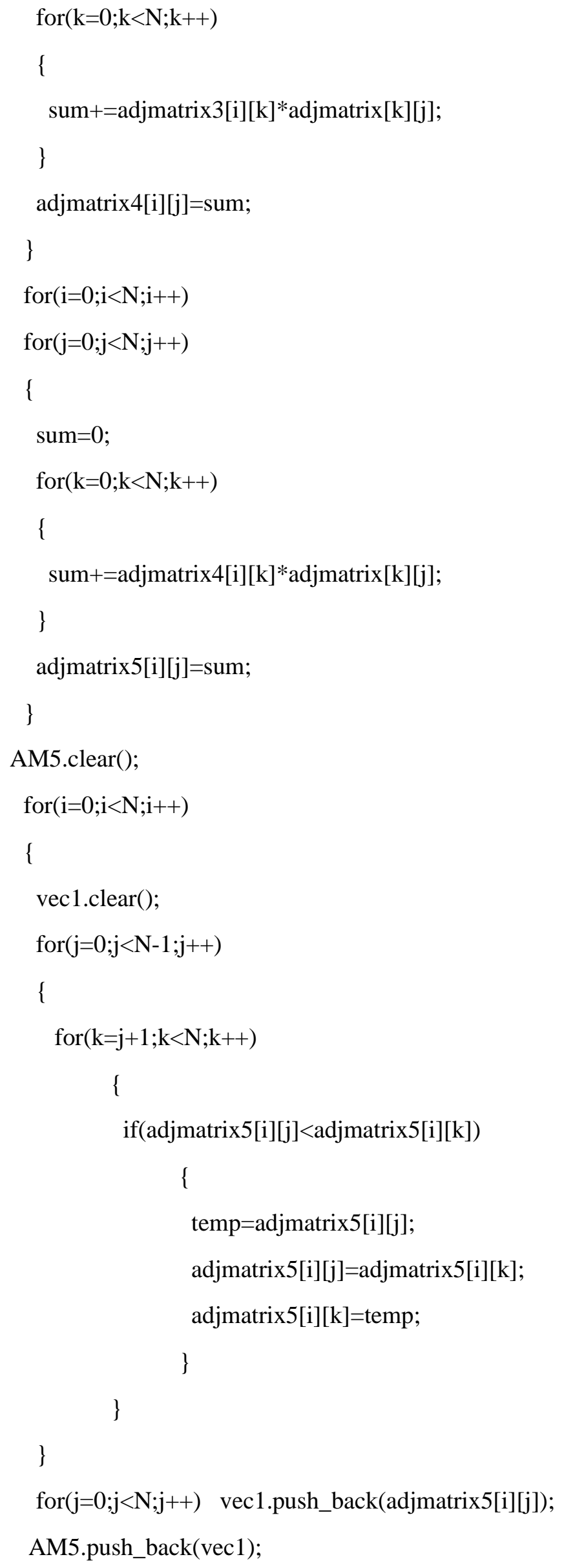




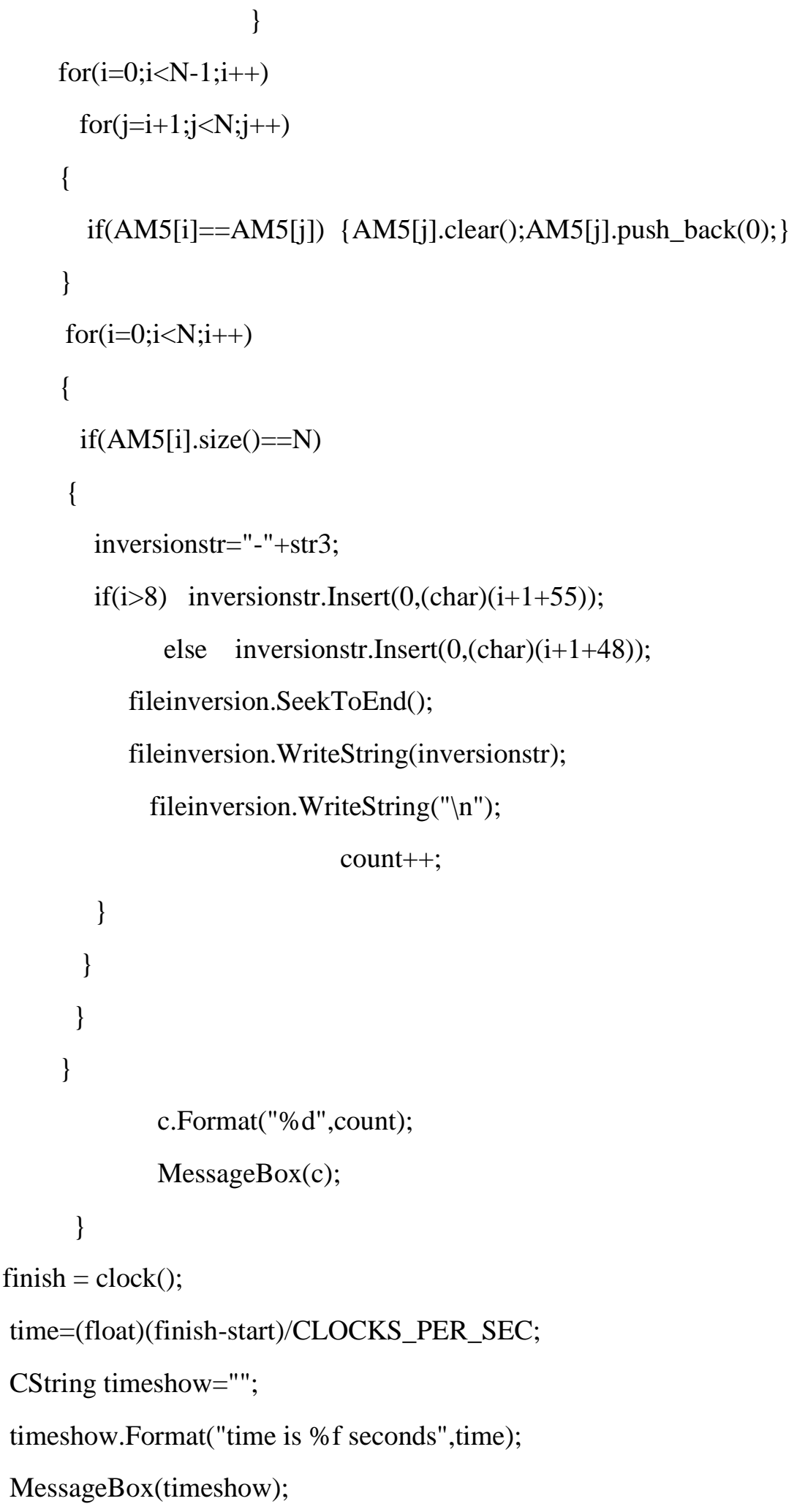

